\title{
Procesos de desplazamiento y desposesión en contextos urbanos. El caso de Sant Antoni (Barcelona)
}

\author{
Laura Caballero Rabanal - Universitat Autònoma de Barcelona
}

DOI: https://doi.org/10.5565/rev/periferia.634

\section{Resumen}

En los últimos años, Sant Antoni (Barcelona) ha ganado popularidad como barrio de moda, tomando el relevo de otras áreas del centro de la ciudad, que ya acumulaban experiencia en torno a procesos de gentrificación. Esta fama creciente ha suscitado la atracción de nuevos residentes, visitantes, consumidores e inversores, tanto autóctonos como extranjeros. Este artículo pretende desgranar las consecuencias que conlleva estar en el centro de la escena, reflexionando sobre las transformaciones vividas en el barrio en los últimos tiempos alrededor de cuatro ejes principales (vivienda, comercio, turismo y espacio público), y otorgando especial relevancia al desplazamiento de vecinos derivado de la especulación inmobiliaria.

Palabras clave: especulación inmobiliaria, gentrificación, desplazamiento vecinal, derecho a la vivienda.

Abstract. Displacement and dispossession processes in urban contexts. The case of Sant Antoni neighbourhood (Barcelona)

Recently, Sant Antoni (Barcelona) has gained in popularity as a trendy neighbourhood, taking over from other city centre areas, which already had experience with gentrification processes. This increasing fame has aroused the interest of new residents, visitors, consumers and investors, both nationals and foreigners. This paper seeks to look into the consequences derived from being in the spotlight, reflecting on the transformations happened lately in Sant Antoni around four main categories (housing, commerce, tourism and public space), highlighting resident displacement caused by real estate speculation.

Keywords: real estate speculation, gentrification, resident displacement, right to housing.

\footnotetext{
${ }^{1}$ Enviar correspondencia a: Laura Caballero Rabanal, lauracaballerorabanal@gmail.com.
}

Este artículo está basado en la investigación presentada en el trabajo final del máster 'Antropología: investigación avanzada e intervención social' (UAB): David contra Goliat. Procesos de desplazamiento y desposesión en contextos urbanos. El caso de Sant Antoni (Barcelona), dirigido por la Dra. Teresa Tapada Berteli y disponible en https://ddd.uab.cat/record/181877?!n=ca. 
Laura Caballero Rabanal, Procesos de desplazamiento y desposesión en contextos urbanos. El caso de Sant Antoni (Barcelona), perifèria 23(1), junio 2018

revistes.uab.cat/periferia

\section{Introducción}

El barrio de Sant Antoni, situado en el distrito del Eixample de Barcelona y colindante con el centro histórico de la ciudad, ha recibido en los últimos años una creciente atención por parte de diversos medios de comunicación, que se han hecho eco de la transformación acelerada del barrio, concretamente en relación con la apertura de establecimientos dedicados a la restauración, el ocio nocturno y la venta de productos de diseño. Los epítetos gourmet, hípster o moderno han venido acompañando al barrio en los titulares de diversas publicaciones. Recientemente, sin embargo, los artículos que señalaban la popularidad ascendente del barrio se han visto eclipsados por relatos más amargos que daban testimonio del abandono involuntario de sus residentes.

Vecinos y activistas, no solo del barrio de Sant Antoni sino también del resto de Barcelona, han denunciado diversas problemáticas que afectan a un gran número de habitantes de la ciudad, como la subida de los precios de alquiler, el desplazamiento de vecinos, la saturación turística y la incursión de nuevos inversores, principalmente del sector inmobiliario.

La motivación de la investigación sintetizada en el presente artículo nace del deseo de estudiar la relación de variables identificadas en procesos similares, como el incremento de los precios del alquiler, la transformación comercial y el desplazamiento de residentes, así como la creciente fama frente al resto de la ciudad y la llegada de inversores. Además, se trata de un área de la ciudad que hasta el momento no ha sido objeto de estudios de enfoque similar, al contrario que la vecina Ciutat Vella, ampliamente estudiada como paradigma de los procesos de gentrificación y turistificación en Barcelona.

En este sentido, los procesos que se dieron en primer lugar en zonas céntricas de la ciudad han empezado a extenderse a otras áreas que hasta hace un tiempo no se habían visto afectadas.

Este artículo expondrá, en primer lugar, los principales enfoques teóricos sobre los que se fundamenta, para después pasar a presentar los resultados de la investigación 
Laura Caballero Rabanal, Procesos de desplazamiento y desposesión en contextos urbanos. El caso de Sant Antoni (Barcelona), perifèria 23(1), junio 2018

revistes.uab.cat/periferia

y las conclusiones derivadas de éstos.

\section{Principales apuntes teóricos}

\section{Los vínculos entre espacio y capital}

En primer lugar, es imprescindible profundizar en las relaciones de poder que rigen la producción del espacio. Los estudios sobre la geografía del capital se alejan de la visión del espacio como ente vacío y señalan la intervención de las relaciones y prácticas sociales en su producción, del mismo modo que apuntan el papel del espacio en la producción y reproducción de éstas (Franquesa, 2013; Lefebvre, 2013 [1974]). Siguiendo esta línea, es importante destacar que, en un sistema capitalista, el suelo constituye una forma de capital ficticio del que se espera obtener un rendimiento futuro (Harvey, 2012). Podemos observar cómo diversas políticas financieras de carácter neoliberal defienden la incentivación de la inversión privada como forma de dinamizar el crecimiento económico, en detrimento de políticas públicas e ignorando flagrantemente las consecuencias sociales y medioambientales que una desregularización total del mercado conlleva (Harvey, 2012).

El posicionamiento deliberado del sector inmobiliario en el epicentro de la economía por parte de instituciones gubernamentales, representa la necesidad biológica acumulativa del capital mediante la expansión territorial. La propensión capitalista a generar excedentes (en forma de capital o mano de obra) que desembocan en crisis por sobreacumulación (Harvey, 2014) impulsa la respuesta del propio sistema para asegurar su supervivencia. David Harvey (1982) acuñó el término spatio-temporal fix para referirse a esta estrategia de desplazamiento en el tiempo y el espacio de las crisis capitalistas. Consiste en absorber estos excedentes mediante proyectos de desarrollo territorial y ordenamiento geográfico, con el fin de retrasar el colapso inminente que el sistema mismo ha provocado. La dimensión temporal, además, hace referencia al periodo que necesitan estas inversiones constructivas para reportar beneficios y reincorporarse al ciclo del capital.

Huelga decir que estas maniobras expansionistas no son inocuas. El origen de la acumulación primitiva de Marx (1998 [1873]) dio lugar a la acumulación por desposesión, acuñada por Harvey (2003), que introdujo este concepto para 
Laura Caballero Rabanal, Procesos de desplazamiento y desposesión en contextos urbanos. El caso de Sant Antoni (Barcelona), perifèria 23(1), junio 2018

revistes.uab.cat/periferia

referirse a los recurrentes ciclos de desposesión a pequeña y gran escala que han dirigido el devenir de la historia desde el inicio del capitalismo, desde la privatización de recursos naturales, culturales e intelectuales, hasta las políticas de austeridad y las ejecuciones de desahucios que marcan nuestra actualidad.

Otro de los pilares sobre los que se fundamenta el sistema capitalista es la sacralización de la propiedad privada, esto es, "la legitimación y racionalización institucional post facto de esa violencia de desposesión" (Harvey, 2014, p.70). Esta percepción de la propiedad individual como algo indiscutible ha calado profundamente en nuestros esquemas culturales, encontrando apoyo en las legislaciones y constituciones estatales, que se fundamentan sobre un esquema de titularización de bienes. Gran parte de las políticas de vivienda en España se han basado en esta tesis para acabar diseñando un panorama habitacional controlado prácticamente en exclusiva por el libre mercado.

\section{Las políticas de vivienda en España}

España cuenta con una tradición de compra de vivienda que deja en segundo plano al alquiler: frente a una media europea de tenencia en propiedad del 73\%, España presenta una media del $85 \%$, mientras que por lo que respecta al arrendamiento de vivienda, la media española se sitúa en el $13 \%$, diez puntos por debajo del promedio europeo. Otro de los datos más significativos es el índice de viviendas de alquiler protegido en España, que no alcanza el 2\%, situándose muy por debajo de la media europea ( $9 \%)$, y más aún si lo comparamos con otros países como Países Bajos, (32\%) o Austria (23\%) (García y Janoschka, 2016).

Es común encontrar la creencia generalizada de que esta preferencia por la compra de vivienda responde a hábitos culturales que relacionan el alquiler con una inversión a fondo perdido, pero si nos detenemos a analizar las políticas de vivienda en España en el último medio siglo, podremos observar que este desequilibrio vino instigado desde el gobierno estatal.

José Luis Arrese, ministro de vivienda franquista (1957-1960) pronunció en plena dictadura (1959) lo que se convertiría en un verdadero objetivo del régimen: Queremos un país de propietarios, no de proletarios. 
Laura Caballero Rabanal, Procesos de desplazamiento y desposesión en contextos urbanos. El caso de Sant Antoni (Barcelona), perifèria 23(1), junio 2018

revistes.uab.cat/periferia

Este menoscabo de la figura del proletario y este afán por convertirlo en propietario tenía como objetivo la reducción del carácter revolucionario del obrero. Como bien apunta el arquitecto urbanista Ramón Betrán (2002), en el momento en el que el trabajador contrae una deuda significativa, y si además tiene familia, rebaja automáticamente su tono reivindicativo.

En los años cincuenta, el régimen de tenencia en propiedad en España era del $49 \%$ y el alquiler ascendía al $41 \%$. En el inicio de la crisis, en 2007 , estas cifras habían dado un vuelco revelador: el $87 \%$ de hogares españoles vivían en una vivienda propia, mientras que el porcentaje de alquiler había disminuido hasta un $7,6 \%$ (Palomera, 2014). La respuesta a semejante fluctuación reside en las políticas de vivienda implementadas en este periodo.

Durante la dictadura franquista, políticas de alquiler basadas en la prórroga forzosa de contratos y la congelación de rentas en periodos de inflación (Ley de Arrendamientos Urbanos, 1946) o las restricciones en la actualización de las rentas en nuevos contratos (LAU 1964) mermaron la oferta de vivienda arrendada y contribuyeron al deterioro de estas fincas, debido a que los propietarios dejaron de invertir en su conservación por considerar su alquiler una opción poco provechosa (Leal, 2005; Palomera, 2014).

En el año 1985, el Real Decreto del ministro Boyer dio un giro total a la situación de la vivienda arrendada en España: medidas liberales como la eliminación de la prórroga forzosa de los contratos y de las restricciones en el aumento de la renta no hicieron otra cosa que desproteger al inquilino (Palomera, 2014).

Más recientemente, en 2013, la reforma de la LAU de 1994 por parte del Partido Popular redujo la duración mínima de los contratos de alquiler de cinco a tres años, y su prórroga anual una vez finalizado este plazo, de tres a uno, con el objetivo de flexibilizar y dinamizar el mercado, como afirma su preámbulo. Sin embargo, esta dinamización ha colocado en una posición aventajada al propietario, que a partir de esta reforma ha podido aumentar las rentas o no renovar contratos en un menor periodo de tiempo.

El periodo desarrollista del Franquismo creó un gran parque de vivienda protegida 
Laura Caballero Rabanal, Procesos de desplazamiento y desposesión en contextos urbanos. El caso de Sant Antoni (Barcelona), perifèria 23(1), junio 2018

revistes.uab.cat/periferia

subvencionada que, sin embargo, no estaba destinada al alquiler sino a la compra (Palomera, 2014), dando muestra, de nuevo, de su deseo de incentivar la propiedad privada del hogar. Al cabo de un cierto periodo de tiempo, estas viviendas pueden descalificarse de su régimen protegido e incorporarse al mercado libre, lo cual supone un trasvase de fondos públicos a manos privadas, a fondo perdido y sin retorno (García y Janoschka, 2016).

Otro ejemplo del enfoque neoliberal de las políticas de vivienda en España (y otros países) son las medidas de atracción de inversión extranjera mediante los conocidos como golden visas o visados dorados, que conceden permisos de residencia a quien adquiera propiedades inmobiliarias por valor igual o superior a 500.000 euros.

De cualquiera de las maneras, el acceso a la vivienda está marcado por la intervención de una entidad de crédito, lo cual acaba por constituir un elemento de control, una "expropiación financiera" de trabajadores y sectores no capitalistas (Lapavitsas, 2009, en Palomera, 2014, p.220), que se ven obligados a formar parte de este circuito financiero. La incorporación de rentas bajas y medias en el circuito del capital a través de este sistema único basado en la deuda hipotecaria ha posibilitado la libre circulación de valores a través de casi todo el territorio urbano (Rolnik, 2015). Esta financiarización de la vivienda puede observarse, además, en el uso de la vivienda privatizada como garantía para obtener más crédito financiero o participar en inversiones, "transitando" como una mercancía más (Rolnik, 2015).

Como conclusión podemos extraer que las políticas de vivienda españolas de los últimos cincuenta años han sido diseñadas con un marcado corte neoliberal que ha dado preeminencia al beneficio de los poderes financieros por encima del bienestar social, sirviendo a objetivos contradictorios: garantizar el acceso a la vivienda y dinamizar la economía reduciéndola al sector de la construcción, dando prioridad a su valor de cambio por encima de su valor de uso (García y Janoschka, 2016). Por otra parte, mediante la promoción de la privatización de la vivienda, el Estado deja en manos del ciudadano la responsabilidad gubernamental de cubrir este derecho básico, a la vez que delega el control de su provisión (y potencial explotación) en el libre mercado (Palomera, 2014), dando pie a una batalla desigual librada entre el individuo y las fuerzas del capital. 
Laura Caballero Rabanal, Procesos de desplazamiento y desposesión en contextos urbanos. El caso de Sant Antoni (Barcelona), perifèria 23(1), junio 2018

revistes.uab.cat/periferia

\section{Gentrificación y desplazamiento: los significados del espacio en la identidad individual y colectiva}

La transición de la austeridad funcional característica de la arquitectura y el urbanismo modernos al interés por la estética típico del posmodernismo arquitectónico impulsó de cierta forma la acumulación del capital simbólico, tal y como denominado por Bourdieu (1977, 1984, en Harvey, 1990). Siguiendo este hilo, Harvey señala que la posesión de bienes de lujo busca atestar la distinción de su dueño/a, ocultando que no son más que el producto de la transformación del capital monetario, encubriendo, a la vez que ayudando a reproducir, las diferencias de clase sobre las que este capital se fundamenta.

En el área de la vivienda nos encontramos con algo parecido: Díaz Parra (2014), haciendo referencia al tributo diferencial de Lipietz, apunta que la burguesía y las clases medias "pagan el derecho a no cohabitar con cualquier persona", lo cual favorece la división social del espacio, excluyendo a los sectores menos pudientes mediante la renta monopólica de clase (Harvey, 1977, en Díaz Parra, 2014).

Esta reflexión nos ayudará a introducir uno de los fenómenos urbanos más polémicos que ha tomado especial fuerza fuera de los circuitos académicos en los últimos años: la gentrificación, cuyo efecto más directo, aunque también menos visible, es el desplazamiento de residentes, en el que me detendré más adelante.

Desde que surgiera el concepto de gentrificación, acuñado en 1964 por Ruth Glass en su investigación sobre la expulsión de residentes de clases bajas del centro de Londres y su sustitución por clases medias de mayor poder adquisitivo, la controversia alrededor del mismo no ha cesado. Los procesos de gentrificación en contextos urbanos, pese a contar con características propias, se han ido repitiendo en diferentes puntos del planeta. La diversidad de causas y consecuencias de cada proceso gentrificatorio ha hecho que este fenómeno fuera definido como un "concepto caótico" (Van Weesep, 1994, en Sargatal, 2000). No obstante, en los inicios de los estudios sobre gentrificación, surgieron dos corrientes principales que configuraron las teorías clásicas alrededor de este concepto (Sargatal, 2000; Sequera, 2015).

El contexto en el que surgieron estas teorías era el del retorno de las clases medias 
Laura Caballero Rabanal, Procesos de desplazamiento y desposesión en contextos urbanos. El caso de Sant Antoni (Barcelona), perifèria 23(1), junio 2018

revistes.uab.cat/periferia

desde los suburbios residenciales al degradado centro de la ciudad posindustrial, habitado por residentes de bajo poder adquisitivo. Este retorno ha recibido, por parte de diferentes estudiosos, apelativos como "reconquista urbana" (Castells, 1977) o "ciudad revanchista" (Smith, 1996), que hacen referencia a la históricamente omnipresente lucha de clases.

Como máximos referentes de cada uno de los dos enfoques teóricos principales encontramos a David Ley y Neil Smith. El primero (Ley, 1978, en Smith, 1979), desde una perspectiva culturalista, defiende que el principal detonante de un proceso de gentrificación es la demanda por parte de los miembros de una nueva clase de la sociedad posindustrial (white collars), esto es, profesionales dedicados al sector servicios que cuentan con una base económica sólida (Sargatal, 2000), cuyo capital cultural y gusto por la estética influyen, junto con el papel activo del gobierno en materia urbanística, en la revalorización del suelo en determinadas zonas.

Por su parte, Neil Smith, aplicando un enfoque neomarxista, y sin dejar de tener en cuenta el papel de los consumidores, señaló la oferta como elemento clave para el inicio de un proceso de gentrificación: es la búsqueda de beneficio por parte de los agentes del suelo (promotores, inversores y gobiernos) lo que incentiva su estallido. Su teoría del rent gap, o diferencial de renta (1979) explica la rentabilidad de reinvertir en determinadas zonas urbanas degradadas: el concepto de rent gap hace referencia a la diferencia entre la renta del suelo capitalizada actual y la potencial que podría obtenerse mediante un uso más lucrativo de éste. Llegados al punto en el que esta brecha cuenta con dimensiones considerables, la rehabilitación empieza a ser rentable, y con ello, aumentan exponencialmente las posibilidades de que se inicie un proceso de gentrificación. En el contexto de estudio de Smith, los centros urbanos abandonados constituían un caldo de cultivo excelente para los fenómenos gentrificatorios. Este abandono, además, vendría impulsado por los procesos de inversión-desinversión de organismos públicos y privados (Smith, 1979, p.543), que con sus operaciones mercantiles preparan el escenario del desplazamiento de residentes.

Tal y como mencionado anteriormente, el desplazamiento ha sido reconocido como una de las consecuencias más directas a las que conduce un proceso de 
Laura Caballero Rabanal, Procesos de desplazamiento y desposesión en contextos urbanos. El caso de Sant Antoni (Barcelona), perifèria 23(1), junio 2018

revistes.uab.cat/periferia

gentrificación. Peter Marcuse (1985) estudió ampliamente estos fenómenos, sentando las bases de una clasificación de los diferentes tipos de desplazamiento.

En primer lugar, basándose en la definición de los Grier (1978, en Marcuse, 1985), el desplazamiento directo puede tomar dos formas: física (p.ej., el propietario corta la calefacción) o económica (p.ej., subida del alquiler). A esto, Marcuse propone otras dos categorías: el desplazamiento por exclusión remite a la imposibilidad de una unidad familiar para acceder a una vivienda abandonada o gentrificada, aunque antes de producirse este proceso de abandono o gentrificación reuniera los requisitos de acceso a dicha vivienda; por otro lado, la presión de desplazamiento incluye todos aquellos factores que influyen en el abandono "voluntario" de los residentes, tales como la ruptura de redes sociales y comerciales por el abandono de vecinos o el cierre de comercios, o los cambios en instalaciones y servicios públicos (p.207).

Numerosas voces desde la academia han señalado las dificultades que comporta cuantificar el desplazamiento (Marcuse, 1985; Rubiales, 2014). Otras, sin embargo, han tratado de restarle importancia o incluso de negar su existencia ante la imposibilidad de reunir datos cuantitativos suficientes (Rubiales, 2014). En ocasiones, se ha naturalizado como un proceso gradual de reemplazo de una reducida clase trabajadora por parte de una emergente clase media profesional (Hamnett, 2003). Esto ha recibido fuertes críticas que condenaban la falta de interés institucional por investigar en profundidad los casos de desplazamiento (García, Smith y Mejías, 2007; Slater, 2006).

Los estudios acerca de la identidad y apropiación del lugar nos ayudan a entender los estragos que el desplazamiento provoca a nivel personal y social. La apropiación del espacio que conduce al apego al lugar se desarrolla a través de dos procesos complementarios, según Vidal y Pol (2005): la acción-transformación, mediante el cual los individuos intervienen en el espacio y lo transforman, incorporándolo en sus procesos cognitivos y afectivos, y la identificación simbólica, que permite a persona y grupo reconocerse en el entorno.

Por lo que respecta a la casa, ésta no solo actúa como protectora de aquéllos a los que cobija, sino que también sirve como punto central de referencia espacio-temporal de sus habitantes, formando así parte de su identidad (Giglia, 2012). 
Laura Caballero Rabanal, Procesos de desplazamiento y desposesión en contextos urbanos. El caso de Sant Antoni (Barcelona), perifèria 23(1), junio 2018

revistes.uab.cat/periferia

\section{Gentrificación y promoción turística}

Las investigaciones acerca de los fenómenos de gentrificación en zonas turísticas coinciden en la crítica a las políticas municipales de promoción de una ciudad o barrio (especialmente, centros históricos) cuyo fin es atraer turismo e inversiones, hasta convertir ese espacio en un área dedicada al ocio y al consumo de forma casi exclusiva (Cócola, 2016a; Hiernaux y González, 2014).

En el caso de Barcelona, la promoción de la ciudad como destino turístico se remonta a principios del siglo $X X$, impulsada por políticos y emprendedores pertenecientes a la burguesía. Poco a poco, diferentes medidas fueron configurando la imagen de marca de Barcelona como ciudad de vacaciones ${ }^{2}$ (Palou, 2012).

A mediados del siglo XX, la "medievalización" del casco histórico de la ciudad, que revirtió la destrucción de patrimonio realizada años atrás para responder a necesidades productivas industriales, sirvió para crear un símbolo de identificación ciudadana colectiva e incrementar el atractivo turístico de la ciudad (Cócola, 2010).

Esta labor de proyección internacional encontró su colofón en los Juegos Olímpicos de 1992, que posteriormente trataría de repetirse con el Fórum de las Culturas 2004, tomando el relevo del último alcalde franquista de Barcelona, Josep Ma de Porcioles (1957-1973), cuyo objetivo era convertir la ciudad en un destino de "ferias y congresos" (Delgado, 2007).

En el sector inmobiliario, la especulación turística no se hace esperar. Dejando de lado la concentración hotelera en espacios turistificados, en los últimos tiempos ha aparecido una nueva frontera en el horizonte de la vivienda, autoclasificada dentro de la "economía colaborativa": el subarriendo de habitaciones y pisos para uso turístico mediante plataformas como AirBnB ha supuesto una ruptura de esquemas

\footnotetext{
2 Aunque inicialmente este impulso turístico se encontró con varios obstáculos (falta de infraestructuras y apoyo institucional y ciudadano). la apertura de la primera oficina de turismo, la puesta en escena de la ciudad mediante eslóganes publicitarios y la implantación de un discurso hegemónico que ensalzaba el turismo iniciaron la proyección internacional de la ciudad-marca (Cócola y Palou, 2015).
} 
Laura Caballero Rabanal, Procesos de desplazamiento y desposesión en contextos urbanos. El caso de Sant Antoni (Barcelona), perifèria 23(1), junio 2018

revistes.uab.cat/periferia

en torno al alojamiento turístico. La injerencia de quienes están permanentemente ojo avizor para captar cualquier oportunidad nueva de negocio, apoyados por la falta de regulación legislativa en este aspecto, junto con el enfoque de ciertas políticas económicas basadas en la explotación turística y la liberalización del mercado inmobiliario, ha contribuido a acelerar en los últimos años el desplazamiento de residentes (Cócola, 2016b; López-Gay y Cócola, 2016).

La idea generalizada de que el turismo genera riqueza económica cuenta con poderosos argumentos que la desmontan. Esta riqueza puede observarse en los grandes índices, que lejos de ser distribuidos entre la población, corresponden a ingresos percibidos por grandes corporaciones (Sequera, 2015). Por otro lado, la precariedad laboral en el sector del turismo y la hostelería provoca que muchos de sus trabajadores no puedan prácticamente aportar impuestos a las arcas públicas, aunque necesiten acceder a servicios que suponen un gasto importante de fondos públicos. El Estado, en lugar de obtener ingresos gravando los grandes capitales, subvenciona a grandes aerolíneas y empresas hoteleras, construyendo un ciclo de sentido único de transferencia de fondos públicos a manos privadas (entrevista a Agustín Cócola realizada con motivo de esta investigación. Lisboa, 13 de junio de 2017).

La gentrificación derivada de la turistificación de un espacio está estrechamente relacionada con la llamada 'gentrificación comercial'. Los cambios en el tejido comercial conducen a establecimientos dirigidos a un público de poder adquisitivo más elevado, o a turistas. En ocasiones, los productos que comercializan ni siquiera son útiles para los residentes de la zona, quienes observan el cierre progresivo de los comercios de proximidad y la llegada de franquicias o establecimientos pertenecientes a cadenas. A esto hay que añadir la invasión del espacio público por parte de terrazas de bares y restaurantes, o la aparición de numerosos locales de ocio nocturno, que influyen en la vida cotidiana de los habitantes permanentes (Cócola, 2016b) e intensifican la presión de desplazamiento descrita por Marcuse (1985) al cortar las relaciones sociales con los comercios conocidos y la desaparición de usos y servicios necesarios. 
Laura Caballero Rabanal, Procesos de desplazamiento y desposesión en contextos urbanos. El caso de Sant Antoni (Barcelona), perifèria 23(1), junio 2018

revistes.uab.cat/periferia

\section{El caso del barrio de Sant Antoni: presentación y análisis de resultados}

La investigación presentada en este artículo se llevó a cabo entre octubre de 2016 y mayo de 2017. Durante ese tiempo asistí a algunas reuniones y actos convocados por la plataforma vecinal Fem Sant Antoni ${ }^{3}$ (en adelante, FSA), cuyos debates tenían como eje principal el turismo y la vivienda en el barrio. Me sirvió para acercarme a la realidad del barrio y para conocer de primera mano algunos testimonios de vecinos que acudían a explicar situaciones de expulsión inminente. Paralelamente, entre marzo y junio, realicé una serie de entrevistas a diferentes perfiles de interés, reunidos en la siguiente tabla:

\begin{tabular}{|c|c|c|c|}
\hline \multicolumn{5}{|c|}{ RESIDENTES } \\
\hline Entrevistado & Sexo y edad & $\begin{array}{c}\text { Tiempo de residencia } \\
\text { en el barrio }\end{array}$ & $\begin{array}{c}\text { Relación con alguna entidad } \\
\text { asociativa del barrio }\end{array}$ \\
\hline E1 & Hombre, 44 años & 8 años & FSA \\
\hline E2.1 & Hombre, 29 años & 1 año y cuatro meses & (Residente de Sant Antoni) \\
\hline E2.2 & Mujer, 25 años & 1 año y cuatro meses & (Residente de Sant Antoni) \\
\hline E3 & Hombre, 56 años & 30 años, aprox. & FSA \\
\hline E4.1 & Mujer, 86 años & 64 años & (Residente de Sant Antoni) \\
\hline E4.2 & Hombre, 88 años & 64 años & (Residente de Sant Antoni) \\
\hline E5 & Hombre, 63 años & 40 años, aprox. & FSA \\
\hline E6 & Mujer, 31 años & 7 años & (Exresidente de Sant Antoni) \\
\hline \multicolumn{5}{|c|}{ EXPERTO } \\
\hline $\begin{array}{l}\text { Agustín Cócola Gant, investigador posdoctoral (Centro de Estudios Geográficos, } \\
\text { Universidad de Lisboa) }\end{array}$
\end{tabular}

Las entrevistas fueron individuales excepto en dos casos, que fueron en pareja. Los perfiles pretenden ser lo más variados posible respecto a las variables presentadas en la tabla. Entre los entrevistados figuran dos casos de desplazamiento (E3-en proceso en el momento de la entrevista, y E6-concluido) y dos residentes muy activos en el tejido asociativo del barrio que conocen de primera mano numerosos casos de expulsión y desplazamiento en Sant Antoni.

\section{La cuestión de la vivienda. Desplazamiento(s) de vecinos en Sant Antoni}

\footnotetext{
${ }^{3}$ Aprovecho la ocasión para mostrar mi agradecimiento a Fem Sant Antoni y subrayar el valor de su función como colectivo vecinal.
} 
Laura Caballero Rabanal, Procesos de desplazamiento y desposesión en contextos urbanos. El caso de Sant Antoni (Barcelona), perifèria 23(1), junio 2018

revistes.uab.cat/periferia

La vivienda es, indudablemente, el eje principal de este estudio, que gira en torno a las transformaciones socioespaciales del barrio de Sant Antoni, tratando de identificar algunas de sus causas y, especialmente, los efectos sobre sus residentes.

Desde el inicio de la crisis, la falta de crédito hipotecario y las oleadas de desahucios han conducido a muchas personas a la opción del alquiler. El hecho de que el precio del alquiler en Barcelona haya aumentado en los últimos cuatro años a un ritmo anual del 10-15\% (entrevista a Agustín Cócola, 13/06/2017) ha afectado a gran parte de los inquilinos de la ciudad.

Me basaré en la clasificación de los diferentes tipos de desplazamiento elaborada por Peter Marcuse (1985), explicada anteriormente, para dibujar el contexto del barrio que nos ocupa. En el caso de Sant Antoni, el desplazamiento directo se materializa en un aumento del precio del alquiler inasumible por el arrendatario o en la no renovación del contrato. En algunos de los casos conocidos, el aumento es tan elevado que lleva a pensar que el propietario era consciente de que el inquilino no podría aceptarlo y acabaría por marcharse. Este tipo de desplazamiento ha recibido el nombre de "desahucios invisibles" por parte de los colectivos de vecinos, ya que, aunque no constan como tal, son la forma más directa de desplazamiento.

Existe un perfil de residente en Sant Antoni al que se han referido varios de los entrevistados: familias jóvenes con hijos en edad escolar. En ciertos casos, estas familias aceptan la subida del alquiler para que sus hijos no tengan que interrumpir el curso escolar, por lo que se ven obligados a destinar una mayor cantidad de sus ingresos a la vivienda, a costa de reducir sus ahorros o sus gastos en otras cuestiones. Estos procesos suelen ser bastante precipitados, por lo que las decisiones de aceptar el aumento de la renta o abandonar el barrio sin poder plantearse más opciones se toman sin disponer de mucho tiempo para reflexionar, como apunta uno de los informantes:

E5: I també, aquests que et dic que son els més afectats pel desnonament invisible, aquesta generació que té fills (...) si al final arriba a la conclusió de que ha de marxar, doncs dedica les energies a buscar un altre lloc per marxar, i tampoc lluita. (...) Tu no pots deixar la teva vida, no et pots deprimir, no pots deixar de portar els nens, no pots deixar de treballar (...) És una situació que 
Laura Caballero Rabanal, Procesos de desplazamiento y desposesión en contextos urbanos. El caso de Sant Antoni (Barcelona), perifèria 23(1), junio 2018

revistes.uab.cat/periferia

dintre de 3 anys s'hi tornarà a trobar (...) estàs condemnat a ser un nòmada. (...) Com a molt, o fins i tot, treballant els dos, el sou d'un ja se'n va a prendre pel sac. I si tens fills, vas escanyat.(...) Per això et dic que és un empobriment de la gent, que fins $i$ tot, tenint un sou digne, amb aquests lloguers, ets un pobre.

Los propietarios experimentan la ilusión del "crecimiento infinito" tan propia del capitalismo, que les lleva a tratar de aprovechar al máximo la situación de ascenso de los precios antes de que vuelva a estallar la burbuja. Su deseo de acumulación de capital pasa por encima de cualquier lógica matemática sobre la relación entre la media de los salarios y los alquileres.

Por otra parte, la compra de edificios enteros por fondos de inversión y empresas inmobiliarias tiene una gran influencia en el desplazamiento de residentes. Estas operaciones suelen tener un trasfondo especulativo que utiliza transacciones complejas, también conocidas como "pases". Como explica un especulador en una entrevista ${ }^{4}$, un inversor puede comprar un edificio formalizando un contrato de arras y pagando un pequeño porcentaje del precio total en concepto de paga y señal. Durante el plazo del que dispone antes de abonar el resto, incrementará el valor del edificio: primero, vaciándolo de inquilinos, tras lo cual lo revenderá a otro inversor que se encargará de otro paso de la revalorización (p.ej. reformas en los pisos), obteniendo un beneficio significativo en poco tiempo, y así sucesivamente hasta llegar al inversor que finalmente alquilará o venderá las viviendas a un precio inflado tras estos movimientos. Según lo observado en Sant Antoni, los destinatarios serán probablemente residentes con un mayor poder adquisitivo, o turistas, estudiantes o profesionales que permanecerán en Barcelona durante una temporada, ya que un alquiler temporal o por habitaciones es mucho más rentable que uno a largo plazo a un núcleo familiar.

El desplazamiento por exclusión suele tomar el relevo de este desplazamiento directo. En la actualidad, los precios han aumentado especialmente, con lo cual, en muchas

${ }^{4}$ http://www.huffingtonpost.es/2017/03/29/asi-funciona-la-especulacion-inmobiliaria-enbarcelona a 22017385/ 
Laura Caballero Rabanal, Procesos de desplazamiento y desposesión en contextos urbanos. El caso de Sant Antoni (Barcelona), perifèria 23(1), junio 2018

revistes.uab.cat/periferia

ocasiones, el abandono de la vivienda acaba conduciendo al abandono del barrio. Esto les ocurrió a E6 y a sus compañeras de piso, a quienes el propietario del piso no les renovó el contrato argumentando que su hija iba a trasladarse a vivir allí (aunque los vecinos de la escalera tenían la sospecha de que el verdadero fin era convertirlo en un piso turístico):

E6: Porque antes de irnos del barrio estuvimos mirando por el barrio. Porque, claro, después de seis años en el barrio estás a gusto en el barrio (...) el barrio es casa ya, no estás tan de paso ya. Pues eso, entre 1000-1200 [euros].(...) Imposible, imposible.

Por lo general, existe el temor de que el vencimiento de un contrato de alquiler conllevará un aumento elevado o la no renovación de éste, lo cual acarreará el abandono del barrio o incluso de la ciudad.

Continuando la clasificación del desplazamiento de Marcuse (1985), la presión de desplazamiento en Sant Antoni responde a varios factores, y la entrevista a E3 da buena cuenta de ello. Su edificio, en el que lleva de alquiler más de 30 años, cambió de manos dos veces en los últimos cinco años. Estos nuevos propietarios (dos empresas inmobiliarias) han perseguido el mismo objetivo: dejar de renovar contratos de alquiler para vaciar el edificio. Como primera consecuencia, la comunidad de vecinos del bloque, que había construido unos lazos bastante fuertes, se fue desintegrando.

E3: En un període d'un any,(...) tres pisos, on hi havia veïns i amics nostres van desaparèixer. I ens anàvem trobant cada cop més desemparats, no? Per dir-ho d'alguna manera. Perquè, clar, tampoc ho penses quan tens un contracte, que te n'aniràs i sobre tot després de 30 anys, sempre estàs amb la il/lusió de que et renovaran per sempre. Bueno, és una cosa que ens ha vingut a tots com un xoc.

A partir de ese momento, las obras de reforma en los pisos que iban quedando vacíos empezaron a crear molestias entre los vecinos. Una vecina del mismo edificio, que explicaba que al abrir la galería le entraba el polvo de las obras, definió la situación como "un año humillante". 
Laura Caballero Rabanal, Procesos de desplazamiento y desposesión en contextos urbanos. El caso de Sant Antoni (Barcelona), perifèria 23(1), junio 2018

revistes.uab.cat/periferia

Si hasta ese momento los alquileres rondaban los 800 euros, el precio de los pisos vaciados y reformados se duplicó. Algunos de los nuevos inquilinos eran extranjeros que realquilaban habitaciones a turistas. El tránsito de personas hizo que los vecinos veteranos dejaran de saber quién vivía allí o quien estaba de paso. A este respecto, este tipo de situaciones de flujo constante de personas desconocidas genera cierta inseguridad en los residentes de un edificio, especialmente si se trata de personas mayores, ya que la resistencia al cambio en el espacio habitado y cargado simbólicamente se agudiza con la edad (Pol, 1996).

Algunos entrevistados han señalado las relaciones con los nuevos residentes como superficiales, individualistas o carentes de cordialidad, mostrando tiempos pasados en los que el trato entre vecinos era más cercano. Los nuevos habitantes son percibidos como personas que no se asientan ni echan raíces, y que por lo tanto no llegan a pertenecer al barrio.

Las estrategias que siguen las empresas inversoras para mermar la resistencia de los vecinos son variadas, y en ocasiones entran de pleno en la violencia inmobiliaria. Desde cubrir la fachada del edificio con un andamio pese a no ser necesaria ninguna reparación, hasta el abandono completo del mantenimiento del edificio (como ocurrió en otro edificio de Sant Antoni en el que ya solo quedaban inquilinos con renta antigua), se van sumando situaciones que generan sentimientos de exclusión y presión que acaban por borrar incluso la voluntad de continuar residiendo en el barrio:

E3: D'alguna manera estàs sempre amb la "espada de Damocles sobre tu cabeza" i ja no disfrutes. Sembla que tinguis una sentència de mort a sobre $i$ ja no gaudeixes tant, ja tens ganes de marxar.(...) I estic buscant altres possibilitats, però tampoc tinc la il/lusió de que trobaré algo en el barri. Perquè també se'm fa antipàtic el barri ja, d'alguna manera, potser prefereixo provar una altra zona, o no sé... No ho sé encara. I la veritat és que em desborda una mica la cosa, perquè aquesta sensació de comunitat, o aquesta tranquil.litat te la treuen. Aconsegueixen intranquil/litzar-te, això és també bastant desagradable. Però bueno, "es lo que hay".

\section{Transformaciones en el tejido comercial}


Laura Caballero Rabanal, Procesos de desplazamiento y desposesión en contextos urbanos. El caso de Sant Antoni (Barcelona), perifèria 23(1), junio 2018

revistes.uab.cat/periferia

Con respecto a los cambios en los comercios del barrio, los vecinos señalan el cierre de comercios de proximidad por diversas razones: subida de precios de alquiler de los locales comerciales, agravada por una pérdida de beneficios por cambios en el perfil del consumidor; hijos que ya no quieren continuar con el negocio de sus padres; y una progresiva competencia por parte de comercios de nueva apertura, especialmente franquicias y cadenas de supermercados.

El cierre de establecimientos "de toda la vida" no solo supone la pérdida de comercios de uso frecuente, sino que también repercute en la ruptura de las relaciones sociales que tienen lugar en esos espacios.

Las nuevas tipologías comerciales incluyen locales de restauración, ocio nocturno y tiendas especializadas, que han hecho de Sant Antoni el eje de degustación gourmet de la ciudad y han influido en la subida de los precios del barrio, como apuntan varios entrevistados. Esto excluye el acceso de quienes no cuenten con la capacidad económica suficiente para consumir en ellos. Además, algunos vecinos señalan que los productos ofertados no les son de gran utilidad en su día a día.

Por otro lado, el Mercat de Sant Antoni, centro neurálgico del barrio, reabrirá sus puertas próximamente, tras nueve años cerrado por reforma. Por lo observado en las entrevistas y en alguna conversación informal con algún comerciante del mercado, los vendedores han visto en este periodo un descenso de clientela y beneficios, motivado por la crisis económica, el traslado a unas carpas detrás del mercado y la larga duración de las obras que, en un principio, se había previsto que se prolongaran entre cuatro y cinco años. La reapertura del Mercat suscita incertidumbre entre los vecinos de Sant Antoni, que temen que se convierta en un punto de atracción turística, con precios elevados y locales dedicados a la degustación, siguiendo el ejemplo del vecino Mercat de la Boqueria.

\section{Percepción del espacio público y del turismo}

Por lo general, los entrevistados no identificaron grandes cambios en el espacio público, aunque denunciaron la falta de zonas verdes y los altos niveles de contaminación. Los colectivos vecinales luchan por la reconversión de espacios en 
Laura Caballero Rabanal, Procesos de desplazamiento y desposesión en contextos urbanos. El caso de Sant Antoni (Barcelona), perifèria 23(1), junio 2018

revistes.uab.cat/periferia

zonas verdes, y tratan de evitar la "conquista" de las zonas comunes por terrazas privadas de bares y restaurantes.

Con respecto al turismo, aunque los niveles de presión turística en Sant Antoni no llegan a los experimentados en el centro histórico de Barcelona, los entrevistados reconocen una creciente llegada de visitantes, propiciada por la imagen de "barrio de moda", promocionado con eslóganes como "familiar, modesto, tranquilo, para tomar el brunch o el vermut" ${ }^{5}$. En algunos casos, se ha relacionado la llegada de turistas a nivel ciudad con procesos identificados como negativos, como la gentrificación, la perturbación del descanso nocturno o el turismo de borrachera, lamentando que los ciudadanos de Barcelona estuvieran siendo víctimas de su propio éxito.

Ante las acusaciones de xenofobia turística, los colectivos ciudadanos han subrayado que la raíz del problema no es la figura del turista, sino el crecimiento infinito de la oferta y la especulación generada a su alrededor, que juega en detrimento de la permanencia y el bienestar de los ciudadanos.

Uno de los puntos calientes en este sentido es el alquiler de vivienda para uso vacacional. Los factores más destacados son los posibles conflictos derivados de la convivencia en un mismo edificio de residentes permanentes y visitantes ocasionales, que siguen ritmos diarios y nocturnos muy diferentes, y el efecto que la proliferación de los pisos turísticos tiene sobre la subida de los precios del alquiler, causada por la reducción de la oferta residencial, además de la expulsión de vecinos para reconvertir las viviendas en apartamentos turísticos.

La principal plataforma a la que se refieren vecinos y prensa a la hora de hablar de alquiler turístico es AirBnB. Aunque supuestamente se trata de una página en la que se anuncian particulares que ofrecen sus casas, para proporcionar al visitante una "experiencia auténtica y autóctona", se ha demostrado que muchos de los anfitriones son profesionales del sector inmobiliario.

La oferta de viviendas anunciadas incluye pisos con licencia turística, pisos de particulares que se alquilan enteros de forma ocasional y pisos sin licencia que se

\footnotetext{
${ }^{5}$ https://www.airbnb.es/locations/barcelona/sant-antoni
} 
Laura Caballero Rabanal, Procesos de desplazamiento y desposesión en contextos urbanos. El caso de Sant Antoni (Barcelona), perifèria 23(1), junio 2018

revistes.uab.cat/periferia

alquilan con frecuencia ilegalmente. También se incluyen habitaciones de particulares que generan debate y posturas enfrentadas: hay quienes afirman que también suponen un impacto en el valor de los alquileres, mientras que otros reconocen que muchas personas han encontrado en esta vía un ingreso que les permite sobrevivir y pagar el alquiler. Según esto, algunos inquilinos o propietarios afectados por la crisis económica, la precariedad laboral o los precios abusivos de los alquileres, entre otros motivos, han recurrido a plataformas de alojamiento turístico para asegurar su supervivencia, contribuyendo al mismo tiempo a engrasar el motor de la ciudad como espacio exclusivo de consumo. De esta forma, del mismo modo que los regímenes dictatoriales pretendían convertir al proletario en propietario, AirBnB convierte al pequeño propietario en empresario turístico, bajo un marketing basado en una supuesta "economía colaborativa" que tiene como fin la redistribución de los beneficios del turismo entre el grueso de la población, aunque los datos indiquen que gran parte de los propietarios no son particulares (según la página web Inside AirBnB, el $60 \%$ de anfitriones tiene más de un anuncio publicado en la plataforma. Diciembre 2016).

\section{Identidad social barrial y sentido de pertenencia}

Los vecinos de Sant Antoni lo describen como un barrio popular con una identidad propia compartida, a diferencia de otros barrios del distrito (Eixample) en los que este sentimiento de pertenencia no está tan definido.

Los entrevistados que sufren o han sufrido un proceso de desplazamiento denotan una pérdida de esta identidad barrial común, alimentada por una sensación de desprotección y desamparo que reduce su sentido de pertenencia al barrio. Esta percepción no solo se observa en ellos mismos, sino que también predicen una pérdida generalizada de esta identidad de barrio a medida que la población de Sant Antoni se vaya sustituyendo. Estos procesos de expulsión vienen motivados por una avaricia carente de ética que queda patente en la terminología utilizada en el sector inmobiliario para referirse al inquilino al que se desea echar: bicho, que recuerda a términos urbanísticos basados en metáforas sanitarias, como higienización o regeneración, al tiempo que sirve para deshumanizar al inquilino en cuestión.

Esta desposesión de la identidad colectiva toma dos vías, la física, por el despojo del 
Laura Caballero Rabanal, Procesos de desplazamiento y desposesión en contextos urbanos. El caso de Sant Antoni (Barcelona), perifèria 23(1), junio 2018

revistes.uab.cat/periferia

territorio, y la simbólica, por la ruptura de los significados compartidos que en éste tienen lugar.

\section{Conclusiones}

Los factores que intervienen en la subida generalizada de los precios de alquiler son variados, y aunque el estudio aquí presentado no cuenta con la envergadura suficiente para identificarlos todos y explorarlos en profundidad, de él se pueden extraer conclusiones que coinciden con otros estudios de enfoque similar. En primer lugar, es destacable la acción especulativa, a pequeña y gran escala, desde pequeños propietarios a profesionales del sector inmobiliario, a lo que hay que sumar el monopolio del suelo derivado de la propiedad vertical por parte de propietarios únicos, empresas y fondos de inversión.

La financiarización de la vivienda como activo contribuye y se alimenta de la creencia generalizada de que la propiedad y titularización de este bien de primera necesidad otorga la potestad de obtener el máximo rendimiento del mismo, incluso si conlleva el incumplimiento del derecho fundamental ( $y$ constitucional) a tener un techo.

Sin dejar de lado la agencia del consumidor y la fuerza de su demanda, pretendo enfatizar el papel de los productores de la oferta a la hora de reconducir las preferencias de consumo, que influyen notablemente en el devenir de los barrios y de sus vecinos a razón de las fluctuaciones caprichosas del mercado. Son estos agentes del suelo quienes aprovechan ciertas circunstancias preexistentes en beneficio propio (en el caso de Sant Antoni, proximidad al centro, promoción de la ciudad, apertura de establecimientos dedicados al ocio y restauración, inversión municipal en infraestructuras urbanas, inauguración del mercado reformado...), prendiendo la mecha de la gentrificación y el desplazamiento.

Estos actores encuentran un aliado fundamental en la falta de acción institucional para poner coto a la ley del mercado inmobiliario. Las políticas implementadas últimamente por el consistorio barcelonés son limitadas si tenemos en cuenta la emergencia habitacional que denuncian los vecinos de Barcelona. La falta de competencias para incorporar ciertas medidas sociales, junto con una historia de políticas de vivienda de corte neoliberal y privatizador que ha delegado su 
Laura Caballero Rabanal, Procesos de desplazamiento y desposesión en contextos urbanos. El caso de Sant Antoni (Barcelona), perifèria 23(1), junio 2018

revistes.uab.cat/periferia

responsabilidad de protección del derecho a la vivienda en un duelo entre ciudadanos y poderes financieros, ha dibujado el panorama que vivimos en la actualidad.

Partiendo de la base de que cada proceso de gentrificación presenta una serie de características propias que avalan su complejidad, vuelvo a la teoría para comparar el caso de estudio con los postulados de Neil Smith (1979) y Peter Marcuse (1985), totalmente relevantes en la actualidad. En el caso de Sant Antoni, el diferencial de renta, o rent gap, no viene motivado por una situación de abandono o degradación previos, sino que el beneficio potencial resulta de la atracción de residentes con mayor poder adquisitivo y visitantes mediante la promoción turística de la ciudad.

Por otro lado, el desplazamiento no solo afecta a clases de bajos recursos, como encontramos en los ejemplos de las teorías clásicas sobre gentrificación, sino que cada vez afecta más a las que podríamos denominar "clases medias". En la actualidad, el incremento abusivo de precios y la congelación de los salarios hace que trabajadores en activo que cuentan incluso con un sueldo no precario no puedan permitirse vivir en ciertas zonas de la ciudad, que cada vez abarcan más territorio. El precio de la vivienda constituye un baremo de segregación social que reconfigura la composición de la ciudad a pasos agigantados y repercute en los significados compartidos de la identidad social urbana (Valera y Pol, 1994).

Para concluir, cabe destacar el papel de los colectivos y movimientos vecinales, que se encargan de responder a las emergencias sociales gracias a su lucha solidaria e incansable, en muchas ocasiones supliendo responsabilidades correspondientes a los órganos de gobierno. En este caso, la labor llevada a cabo a diario por el colectivo Fem Sant Antoni es el mejor ejemplo para justificar esta afirmación: el apoyo inconmensurable entre vecinos, la recogida y difusión de datos y las acciones de protesta representan la fuerza del tejido social. La organización ciudadana es, sin duda, la clave para la reivindicación de derechos pertenecientes por definición a quienes habitan y hacen la ciudad. 
Laura Caballero Rabanal, Procesos de desplazamiento y desposesión en contextos urbanos. El caso de Sant Antoni (Barcelona), perifèria 23(1), junio 2018

revistes.uab.cat/periferia

\section{Bibliografía}

Betrán Abadía, R. (2002). De aquellos barros, estos lodos. La política de vivienda en la España franquista y post-franquista. Acciones e Investigaciones Sociales, 16, 25-67. https://doi.org/10.26754/ojs ais/ais.200216233

Castells, M. (1977). The Urban Question. A Marxist Approach. Londres: Edward Arnold.

Cócola Gant, A. (2010). El Barrio Gótico de Barcelona. Planificación del pasado e imagen de marca (tesis doctoral). Universidad de Barcelona.

https://doi.org/http://hdl.handle.net/10803/2027

Cócola Gant, A. (2016a). Apartamentos turísticos, hoteles y desplazamiento de población. Informe para el debate sobre el nuevo Plan Especial Urbanístico de Regulación de los Alojamientos Turísticos.

Cócola Gant, A. (2016b). La producción de Barcelona como espacio de consumo. Gentrificación, turismo y lucha de clases. En VV.AA., Cartografía de la ciudad capitalista. Transformación urbana y conflicto social en el Estado Español (pp. 31-56). Madrid: Traficantes de Sueños.

Cócola Gant, A. y Palou Rubio, S. (2015). Tourism promotion and urban space in Barcelona. Historic perspective and critical review, 1900-1936. Documents d'Anàlisi Geogràfica, 61(3), 461-482. https://doi.org/10.5565/rev/dag.266

Delgado, M. (2007). La ciudad mentirosa. Fraude y miseria del "Modelo Barcelona". Madrid: Catarata.

Díaz Parra, I. (2014). La teoría de la renta de suelo II: aplicaciones a la ciudad. Recuperado el 24 de mayo de 2017, de https://isotropia.wordpress.com/2014/01/08/la-teoria-de-la-renta-de-suelo-iiaplicaciones-a-la-ciudad/

Franquesa, J. (2013). Urbanismo neoliberal, negocio inmobiliario y vida vecinal. Barcelona: Icaria. 
Laura Caballero Rabanal, Procesos de desplazamiento y desposesión en contextos urbanos. El caso de Sant Antoni (Barcelona), perifèria 23(1), junio 2018

revistes.uab.cat/periferia

García Herrera, L. M., Smith, N., y Mejías Vera, M. Á. (2007). Gentrification, Displacement, and Tourism in Santa Cruz De Tenerife. Urban Geography, 28(3), 276-298. https://doi.org/10.2747/0272-3638.28.3.276

García Pérez, E., y Janoschka, M. (2016). Derecho a la vivienda y crisis económica: la vivienda como problema en la actual crisis económica. Revista Ciudad y Territorio Estudios Territoriales, 48(188), 213-228.

Giglia, A. (2012). Habitar, orden cultural y tipos de hábitats. En El habitar y la cultura. Perspectivas teóricas y e investigación (pp. 9-26). Barcelona: Anthropos.

Hamnett, C. (2003). Gentrification and the Middle-class Remaking of Inner London, 1961-2001. Urban Studies, 40(12), 2401-2426.

https://doi.org/10.1080/0042098032000136138

Harvey, D. (1982). The Limits to Capital. Oxford: Blackwell.

Harvey, D. (1990). The Condition of Postmodernity. An Enquiry into the Origins of Cultural Change. Cambridge MA: Blackwell.

Harvey, D. (2003). The New Imperialism. Oxford: Oxford University Press.

Harvey, D. (2012). Ciudades rebeldes: Del derecho de la ciudad a la revolución urbana. Madrid: Ediciones Akal.

Harvey, D. (2014). Diecisiete contradicciones y el fin del capitalismo. Madrid: Traficantes de Sueños.

Hiernaux, D., y González, C. I. (2014). Turismo y gentrificación: pistas teóricas sobre una articulación. Revista de Geografía Norte Grande, 58, 55-70. http://dx.doi.org/10.4067/S0718-34022014000200004

Leal, J. (2005). La política de vivienda en España. Documentación Social, 138, 6380.

Lefebvre, H. (2013). La producción del espacio. Madrid: Capitán Swing Libros. (Versión original: 1974) 
Laura Caballero Rabanal, Procesos de desplazamiento y desposesión en contextos urbanos. El caso de Sant Antoni (Barcelona), perifèria 23(1), junio 2018

revistes.uab.cat/periferia

López-Gay, A. y Cócola Gant, A. (2016). Cambios demográficos en entornos urbanos bajo presión turística: el caso del Barri Gòtic de Barcelona. En XV Congreso de la Población Española. Población y Territorio en la Encrucijada de las Ciencias Sociales. Fuerteventura (España): Universidad de las Palmas de Gran Canaria. Servicio de Publicaciones y Difusión Científica.

Marcuse, P. (1985). Gentrification, Abandonment, and Displacement: Connections, Causes, and Policy responses in New York City. Washington University Journal of Urban and Contemporary Law, 28, 195-240.

Marx, K. (1998). El Capital, vol. I. Madrid: Siglo XXI de España. (Versión original: 1873)

Palomera, J. (2014). How did finance capital infiltrate the world of the urban poor? Homeownership and social fragmentation in a Spanish neighborhood. International Journal of Urban and Regional Research, 38(1). https://doi.org/10.1111/1468-2427.12055

Palou Rubio, S. (2012). Barcelona, destinació turística. Un segle d'imatges i promoció turística. Bellcaire d'Empordà: Edicions Vitel.la.

Pol, E. (1996). La apropiación del espacio. En L. Íñiguez y E. Pol (Eds.), Cognición, representación y apropiación del espacio. Col·lecció Monografies Psico/Socio/Ambientals, 9 (pp. 45-62). Barcelona: Publicacions de la Universitat de Barcelona.

Rolnik, R. (2015). Guerra dos lugares. A colonização da terra e da moradia na era das finanças. São Paulo: Boitempo Editorial.

Rubiales, M. (2014). ¿Medir la Gentrificación? Epistemologías, metodologías y herramientas de investigación de carácter cuantitativo y mixto. Working Paper Series (ISSN 2341-2755).

Sargatal Bataller, M. A. (2000). El estudio de la gentrificación. Revista Bibliográfica de Geografía Y Ciencias Sociales Biblio 3W, 228(1992), 1-16. 
Laura Caballero Rabanal, Procesos de desplazamiento y desposesión en contextos urbanos. El caso de Sant Antoni (Barcelona), perifèria 23(1), junio 2018

revistes.uab.cat/periferia

Sequera, J. (2015). A 50 años del nacimiento del concepto "gentrificación". La mirada anglosajona. Revista Bibliográfica de Geografía Y Ciencias Sociales Biblio 3W, 20(1127), 1-23.

Slater, T. (2006). The Eviction of Critical Perspectives from Gentrification Research. International Journal of Urban and Regional Research, 30(4), 737-757. https://doi.org/10.1111/j.1468-2427.2008.00772.x

Smith, N. (1979). Toward a Theory of Gentrification. A Back Movement by Capital, not People. Journal of the American Planning Association, 45(4), 538-548. https://doi.org/10.1080/01944367908977002

Smith, N. (1996). The new urban frontier. Gentrification and the revanchist city. Londres: Routledge.

Vidal, T., y Pol, E. (2005). La apropiación del espacio: una propuesta teórica para comprender la vinculación entre las personas y los lugares. Anuario de Psicología, 36(3), 281-297. 